\title{
Visual perception of the physical affordances of a fire extinguisher using an eye tracking device
}

\author{
Yago Weschenfelder Rodrigues, Edson Sidnei Maciel Teixeira, Dulce de Meira Albach, Dalila Campigotto Weiss, \\ Maria Lucia Leite Ribeiro Okimoto \\ Post Graduate Program in Design, Federal University of Paraná - UFPR \\ e-mails: yagowr5@gmail.com; edson.teixeirı@ifsc.edu.br; dulce.albach@ufpr.br; dalisweiss@gmail.com; lucia.deme@@ufpr.br
}

\begin{abstract}
People who act in emergencies must make decisions based on their perceptions of the environment. Thus, emergency equipment, such as a fire extinguisher, must be identified clearly and quickly (intuitive use). Thereby, this paper presents the visual perception study of a Brazilian extinguisher using Eye Tracking. This case study involves twelve participants who had their eye movements tracked in two different contexts. In the first, participants had no prior information. In the second, they watched a video on the proper use of a fire extinguisher. The visualization differences show that participants changed their viewing points after learning more about the main parts of the product, therefore noticing the physical affordances.
\end{abstract}

Keywords: visual perceptions, physical affordances, intuitive use, emergency, fire extinguisher.

\section{Introduction}

A safe environment is a growing concern, especially in crowded places and high-density residences. This is the purpose of structural and environmental standards as well as security equipment dimensioning. Fire safety, it could be argued, is of particular concern since the relevant standards are aimed at preservation of life. Thus, fire extinguishers may be considered of paramount importance.

In terms of use of fire extinguishers in domestic environments, each country has its own set of rules and regulations regarding their safety standards and use. In Brazil, the State Military Fire Department of Paraná (PARANÁ, 2014) defines 'emergency' as 'a critical situation that endangers life, the environment and property, whether the result of human activity or natural phenomenon, which forces a quick operational intervention." Taking into account the fact that buildings are the responsibility of the respective owners or users, it is up to them to take appropriate action in order to adapt the property to security codes and regulations. Thus, the MFBC - Military Fire Brigade Command advocates for the so called FPSC Fire and Panic Safety Code (PARANÁ, 2011), aimed at protecting the lives of the buildings and hazardous areas occupants in case of fire; prevent the spreading of fire, reduce damage to environment and property; provide means of fire control and suppression; give access conditions for the fire department operations; and provide continuity of services in buildings and hazardous areas.
Considered that in addition to the specific Brazilian laws there is a series of standards that underlie and prepare residential areas for any fire emergency. However, legal compliance and fire extinguisher provision may not guarantee its appropriate use. Since a fire extinguisher is an equipment for occasional use and only in case of emergencies, the possible user may not correctly interpret it. If users do not have the ability or prior training, they may not be able to make the appropriate decision in case of a fire. Thus, visual perception of an eventual use safety equipment, such as a fire extinguisher, becomes relevant. It is necessary for the user not only to understand its operational use, but also to make a quick decision (intuitive use), in a few seconds, since it will always be an emergency.

Thereby, this paper presents the analysis of the visual perception process of a Brazilian residential fire extinguisher in order to identify the focus points of the eye of a potential user, according to the physical affordances theory applied to products. For this, was used an Eye Tracking, device that tracks eye movement when displaying a still image. Thus, participants underwent two visualization tests, the first of which occurred without any prior information, and, the second, after a short time instruction. From this, the study sought to identify if there was any change in the image visualization (perception) by the user, with emphasis on two prominent areas of the product: the most functional and 
complex parts and the main part (cylinder), where quick operating instructions can be found.

\section{Theoretical principles}

\subsection{Risk perception}

The FPSC - Fire and Panic Safety Code (PARANÁ, 2011), highlights the so-called "Risk Perception Sense", defining it as impression or intuitive judgment about the nature or magnitude of a risk. According to the FPSC, the perception about the importance and gravity of a given risk is related to the repertoire of knowledge that the individual acquired during cultural development, as well as the political and moral judgment to the meaning of level of risk acceptable for a given social group. And states, "Risk perception is directly proportional to the degree of social development of a particular population group, considered in its psychological, ethical, cultural, economic, technological and political aspects" (PARANÁ, 2011).

By contrast, Navarro and Cardoso (2005) address the issue from the perspective of cognitive processes involved in risk perception. This, according to the authors, is a phenomenon that takes place at the same time as self-perception, which in turn is integrated to a specific collective context. Thus, behavioral perspective is associated with personal factors related to the cognitive formulation ability, emotional and biological aspects as well as reading and interacting possibilities with the external environment.

The characteristic of risk leads to a configuration of contexts that indicate its suitability, establishing scenarios, actors and various organizations, bringing together supporters that accelerate the pressures for the monitoring of risks, such as associations, social and other segments, political authorities and administrative representatives, institutions and scientists (NAVARRO; CARDOSO, 2005, p. 68).

The risk perception issue is also addressed by Sjöberg (2000), who highlights it as a phenomenon still in search of an explanation. The author emphasizes the fact that some of the tools used to detect risk perception - such as Technical Risk Estimates, Heuristics, Psychometric Model and Cultural Theory - show important updates, to a greater or lesser extent. However, they represent only a small risk perception proportion. In this context, the author suggests a model in which attitude, risk sensitivity and specific fear are used as explanatory variables. Based on a different sort of psychological explanation of risk perception to the relationship between attitude and risk perception, was compared to the usual cognitive analysis of attitude.

As one of the exemplifications that aim to clarify what led him to seek a new model, Sjöberg (2000) presents a study covering a representative sample of the Swedish population. Heuristics questions, with three-target risk: representativeness, availability and anchoring, were studied in a set of fifteen hazards. Respondents were asked to assess the risks on a scale from 0 (no risk at all) to 6 (extreme risk). A drastic difference can be perceived between general risk and personal or family risk, highlighting what the author refers to as phenomenon of "unrealistic optimism". In essence, people often pretend to be less subject to risks when comparing themselves to others, thus creating the denial of risk. It also highlights that denial of risk is a very important aspect of risk perception. The survey members were also asked to rate the degree of control they felt they had on each of the risks and to what extent they could protect themselves against them. Differences between general and personal risks (risk denial) were also detected.

Sjöberg's (2000) study in Douglas and Wildavsky (1982) and Dake $(1990,1991)$ points out issues of Cultural Theory of risk perception, which classifies four types of people and which risks they will choose to be concerned about. They are: egalitarian (technology and environment); individualistic (war and other threats to the market); hierarchical (law and order), and fatalistic (none of the above). The overall dimensions of value applied in this method showed not to be promising for the understanding of risk perception. In this case, were not considered "secondary" factors, such as the education level of the survey panel.

Based on these precepts, this study is distinguished by a product analysis (fire extinguisher) directly related to risk perception issues. With a specific focus on the form of visualization of the communication given by the product, reinforcing that the survey panel was not in real risk, which could have meant a change of reading also associated with the deepening of social and cultural issues emphasized by Navarro and Cardoso (2005) and Sjöberg (2000).

\subsection{The Brazilian fire extinguisher as a product}

A fire extinguisher is a portable or wheeled equipment, designated against fire outbreak and equipped with a mechanism to expel its content, which consists of an extinguishing agent. These agents identify the classification of Brazilian extinguishers; they can be water-based, dry chemical powder and carbon dioxide $\left(\mathrm{CO}_{2}\right)$. According to ABNT (Brazilian Association of Technical Norms) NBR 15808 (ASSOCIAÇÃO..., 2013), these different extinguishers are appropriated for one or more fire classes. These classes have specific identification symbols and colors (Figure 1), as follows:

- Class A: suitable for fires including solid materials such as wood, fabric, paper, rubber, thermosetting plastics and other organic fibers, surface and deep burning, leaving residues; 


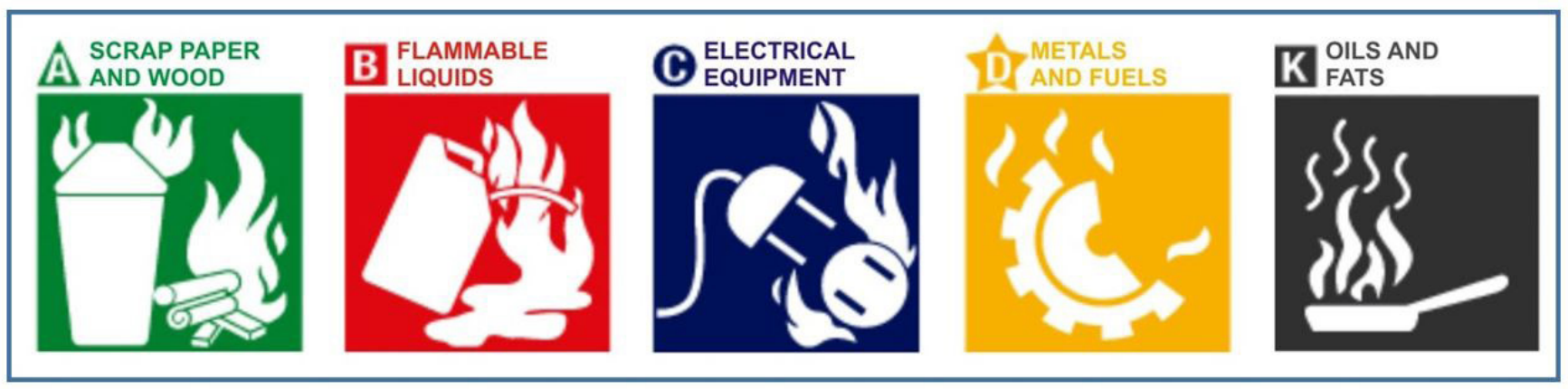

Figure 1. Fire classes. Source: Adapted from CBMDF (CORPO..., 2009).

- Class B: suitable for fire involving flammable liquids and gases or fuels, plastics and greases liquefied by heat, burning only on the surface;

- Class C: suitable for electrical fires including equipment and electrical installations;

- Class D: suitable for metals and fuels, mostly alkaline; and

- Class K: suitable for cooking oils and fats.

The extinguisher specifically for this study is portable, containing dry chemical powder and wall mounted, commonly used in Brazilian residential buildings and efficient for fire classes B and C. Essentially, this type of extinguisher consists of external and internal parts as shown in Figure 2.

- External parts:

- Cylinder: storage container for extinguishing agent. The minimum axial wall thickness of a cylinder must be at least $0.71 \mathrm{~mm}$, and allowed materials are: cold-rolled carbon steel flat, extruded aluminum and austenitic stainless steel. It must receive anticorrosive paint and a finishing coat of red polyurethane based paint;

- Discharge hose: facilitates the release of a steady stream of extinguishing agent from the cylinder. It must be flexible, made out of plastic material or rubber with corrosion resistant ends. It must not show cracks or ruptures, or stifled to decrease its outer diameter in more than $10 \%$;

- Pressure Gauge: indicates the internal pressure at all times. The needle and the dial must be protected by a transparent cover to prevent tampering;

- Trigger: triggers the fire extinguisher;

- Safety pin: ensures locking preventing accidental discharges;
- Carrying lever: serves as support for the pressure on the trigger;

- Seal: guarantees that the extinguisher wasn't used;

- Wall Mount Bracket: enables the display of the extinguisher on the wall and should allow it to be easily removed but have means to prevent accidental falls;

- Identification ring: shows the recharge date and identifies the company responsible in the case of recharged fire extinguishers.

Fire extinguishers must also have a legible instruction label, containing information such as the extinguishing agent; fire class to which the equipment is intended; operating temperature range; degree of extinguishing capability; expiration date; customized manufacturer logo; the lot and the year of manufacture; among others, located on the cylinder.

- Internal parts:

- Extinguishing agent: chemical fire fighter;

- Relief valve: responsible for expelling the extinguishing agent from the cylinder. It must be self-closing, allowing intermittent discharge; and

- Siphon: guides the extinguishing agent to the discharge valve.

Regarding fire extinguishers installation, they should be located in a place of great flow and in plain view of people; near exits and where there is less likelihood of fire blocking access. It should be set at maximum height of $1.60 \mathrm{~m}$ from the floor to the top of the equipment. In Brazilian buildings there must be at least two fire-extinguishing units per floor, unless the area is less than $50 \mathrm{~m}^{2}$. Fire extinguishers should also be allocated based on different types of fire, within its protected area, and evenly interleaved two for the predominant risk and one for a secondary risk protection. 


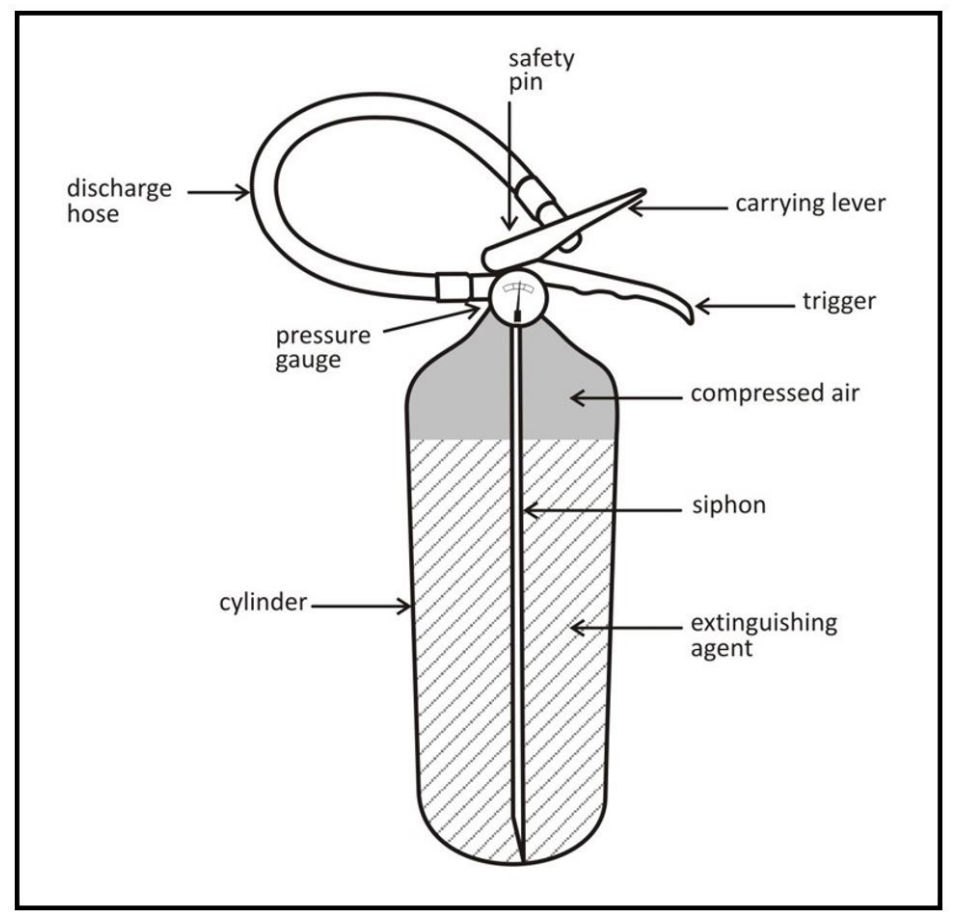

Figure 2. Basic external and internal parts of a Brazilian fire extinguisher. Source: The authors (2016).

A typical fire extinguisher is operated by:

1) Holding the extinguisher upright;

2) Breaking the seal;

3) Pulling the safety pin;

4) Aiming the hose at the base of the fire with an ideal distance of one meter;

5) Pressing the lever.

It is important for the user to be positioned downwind, preventing smoke, and the equipment itself, to become a hindrance. For maintenance, the extinguisher must be recharged annually or whenever, after weighed, there is weight loss beyond $10 \%$ of the original weight.

\subsection{Eye Tracking}

Eye Tracking is a technology based on the monitoring of eye movement. It is based on studies from different field, mainly psychology, which shows that visual perception is an indicator of the prevailing thinking in cognitive processes (JUST; CARPENTER, 1976). Thus, eye position and movement comprise a trace indicating the direction of interest in a certain visual range. The decoding of the ocular track can indicate greater points of interest, as well as the amount of visualization processes applied. Essentially, there are two kinds of eye movements: fixation (visual gaze on a single location) and saccades (rapid focus change). Usually, after a saccade comes a fixation.
Thus, Eye Tracking technology aims to trace saccades and fixation points during the visualization process. It works as an infrared diodes structure that reflects on the corneas and are recorded by image sensors, making the identification exactly at the same moment of the visual perception process. Thus, besides tracking ocular position, the system can interpret points of greater interest, as well as tracks and gazing points (POOLE; BALL, 2006).

The potential application of Eye Tracking technology is very broad and can involve a variety of fields on the perspective of visual interaction data gathering. It extrapolates studies on eye movement verification, with direct interaction benefits for people with mobility disabilities or reduced mobility. Due to its condition as a dynamic visualization verifier, it can also allow the analysis of visual behavior during walks, operational work or television watching. In static analysis, it can be a powerful tool for the understanding of web site design, business ads, packaging or product imagery (DIAS, 2009).

Some studies use eye tracking device as an evaluation tool. Young et al. (2012) found that making the selection of music using a portable player while driving a vehicle increases the amount of time that drivers spend with their eyes off the roadway and decrease their ability to maintain a steady progress position in track. Chen et al. (2014) used the eye-tracking system to assess the risk posture of a child in different settings in the use of mobile information technologies. The authors Yoon, Lim and Ji (2015) conducted a study to investigate the possibility of 
evaluating the perceived visual complexity (PVC) of an instrument panel of a vehicle to estimate and analyze the complexity of their components. Sun et al. (2014) searched for the perception of designers during sketching through eye movements to provide evidence for the Creative Segment theory.

According to Pernice and Nielsen (2009), the use of Eye Tracking requires some care regarding result analyzes. It is necessary a rigorous calibration, tested with pre-visualization targets. This pre-test validates if the visualization targets match the ones spontaneously fixated by the responder. Furthermore, it is important to select the location considering environment comfort and light. It should be taken into consideration if the participants wear contact lenses or glasses, which can interfere with the reflection of the cornea, as well as eye diseases such as cataracts and glaucoma, which can shift the capture of data.

The gathering data methodology using Eye Tracking involves the analysis of the collected data, which can be presented in different forms. Pernice and Nielsen (2009) indicate that results can be grouped, being essentially:

- Gaze replays: consist of watching an eye movement video. This kind of analysis is appropriate to verify the smallest eye movements, with fixation points and saccades of attention and record the participant's face;

- Gaze plots: are graphics indicating eye movement using numbered targets. Thus, identifying the visual track of the participant in order of visualization occurrence. Each numbered target indicates a fixation and the larger the diameter of the target, the greater the length of the fixation;

- Heatmaps: indicate fixation points using a color scale. This analysis allows the identification of the points with higher fixations rates. The red areas indicate higher visualization, which generates the most visual attractive places.

There are still other ways of grouping results, such as Gaze opacity, which is a Heatmap on reverse or Cluster, which are percentages based points. Depending to the equipment used, other kinds of data can also be collected for the interpretation of the results.

\subsection{UX and physical affordances}

Affordance is a term that has gained strength in the literature due to studies in the field of psychology of perception. Gibson (1977) defines affordance as a resource that the environment provides to the animal (observer), which has the ability to perceive and use it. Therefore, affordance is an innate and invariable attribute of the environment / product that can be seen or not by the observer / user.

In addition, Norman (1988) introduced the term affordance to talk about the design of everyday objects referring to an attribute of an object that allows people to know how to use it, in other words, it means "give a hint", if it is noticeable. Therefore, it contributes to the product design field, with the terms affordances "perceived" and "real". The perceived affordances indicate the possibility of actions that the designer wants the user to see in the product, so that they are not necessarily the same as real affordances. On the other hand, the real ones are intrinsic of the product's physical nature and therefore indicate possible primary and natural actions. These are found in physical items, such as holder, which seems to be obvious and don't need to be learned. So, when a user notices the affordance's "tips" about the product, he or she may correctly and intuitively operate the product to complete the tasks of operation, probably without any explanation or direct specification (for some convention or cultural pattern).

Moreover, according to Rebelo (2009), in a more specific context of user interface of products, the term affordance is directly related to the property of an object (of interaction) that offers the user the perception of how to manipulate it in order to access a specific feature.

In functional objects, affordances are directly related to what Lobach (2001) calls practical functions, in other word, the physiological aspects of use, arising from of organic-corporeal relationships between a product and a user. In this sense, when a product is created, its design is conditioned, first to its main use (BROCH, 2010). Thus, it should be perceived as a function belonging to the product.

Similarly, Pucillo and Cascini (2014) show a change in recent decades concerning the concept of usability by ISO 9241-11 (INTERNATIONAL..., 1996) to the ISO 9241-210 (INTERNATIONAL..., 2010), in which the term UX (User Experience) was employed as attitudes, skills, habits and personality of the users regarding their experience. In this light, the approach to evaluate the user experience involves not only efficiency (errors of usage), but also satisfaction (pleasure) and perception while trying the product.

It is worth mentioning a complexity in the definition of UX for the design area, in which projects should not impose behavior, but provide experiences. That is the reason affordances need to be addressed in product designs projects, however, not only with focus on product functions but on how they are perceived.

Hence, as shown in Figure 3, the dimensions for usability (perception, memorization and action) considering the performance and the impression on the products are provided. It is worth noting that before use there is an understanding and questioning about the use. This dynamic 


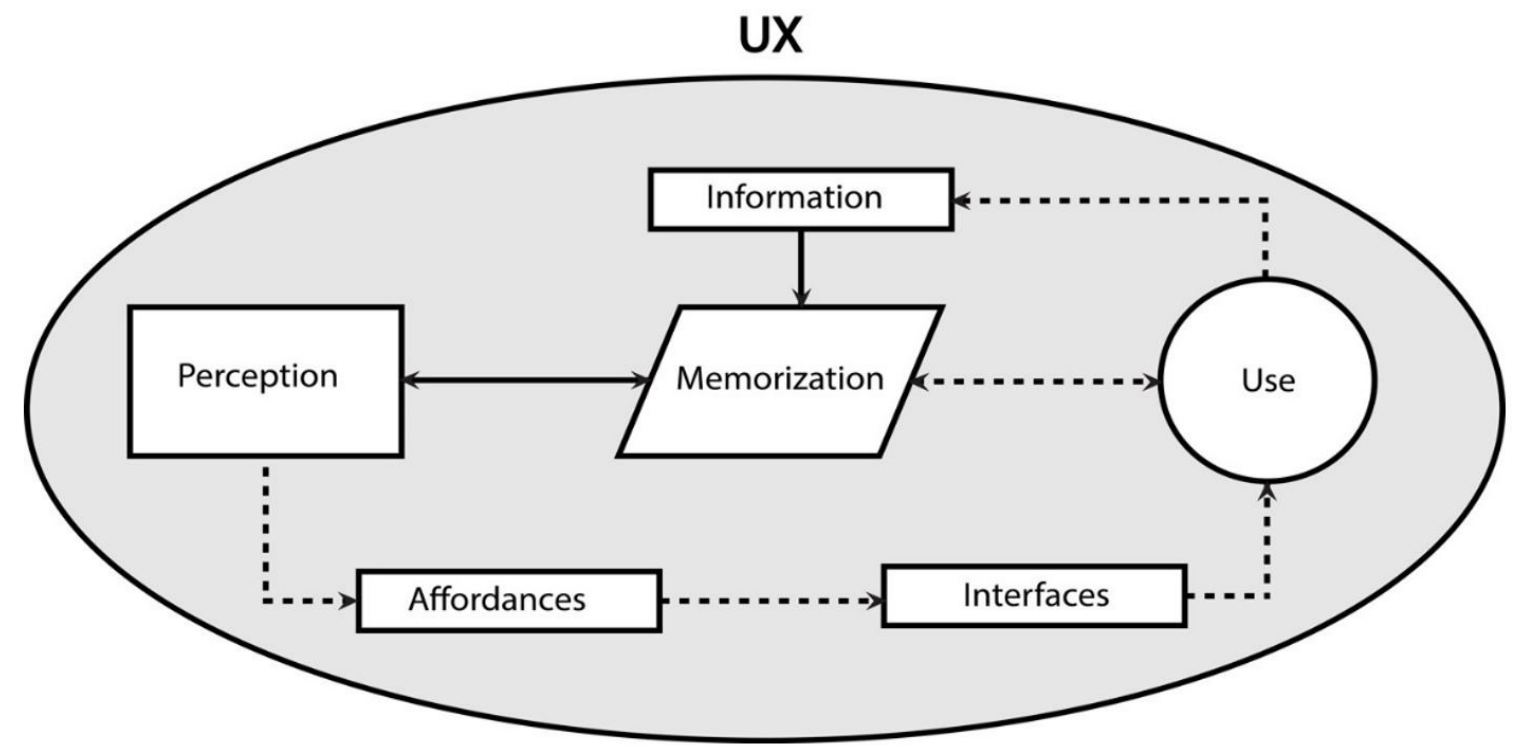

Figure 3. Perception Focus within the UX dimensions. Source: Adapted from Han et al. (2000).

varies according to the situation and product's interaction complexity, considering past experiences with usage information, providing learning (memorization) and changing the perception of the user. Thus begins the perception process of physical affordances of the product, which are immutable. However, being the case of a first contact with the product, it is possible to notice intuitive use occurring.

Similarly, to Silva (2012), perception is identified in the pre-use stage, addressing the intuitive use in relation to the stages of user experience and relating to perception. It starts from sensory stimuli split into visual, auditory and tactile. Furthermore, in pre-use the author considers also the perception of product functionality, being both forms of perception predecessors of use itself. Thus, affordances allow understanding before use, enabling interaction through the interfaces of the product, which provide proper use.

Gaver (1991) was the pioneer on publishing works about the implementation of affordances concepts for the process of HCI (Human Computer Interaction) and pointed that "when affordances are noticeable, they provide a direct link between perception and action"; that is to say, to highlight this attribute in product design is extremely important for optimal intuitive use.

According to Maier and Fadel (2009), the nature of the relationship between products and users is that the products are used by users (which is obvious), but the affordances of products determine how artifacts can be used (which is not obvious). The nature of the relationship between designers and products is that designers create the product affordances. They specify all the properties that will allow a certain set of uses for a given set of users. Thus, the nature of the relationship between designers and users is that designers must validate among users a set of target affordances that must be perceived.

Thus, this research aims to understand the change in the perception of users before physical affordances of a fire extinguisher image using Eye Tracking technology, considering its use in emergencies, which allows little time between perception break and effective use.

\section{Research method}

The research method is defined as an applied case study according to Lakatos and Marconi (2006), focused on an exploratory mixed approach. The evaluation was conducted at the UFPR (Federal University of Paraná) Ergonomics Laboratory, in Brazil, with 12 participants who live in apartments equipped with fire extinguishers; however, none of them could have used one or attended any prior training.

The equipment used for the experiment were a table Eye Tracking with $60 \mathrm{hz}$ and accuracy of 0.5-0.1 degrees The EyeTribe make; a 19-inch notebook and a simple headset for audio.

Regarding the stages, first the participants answered the Informed Consent Form according to the standard ERG BR 1002 (ASSOCIAÇÃO..., 2003) followed by the beginning of the first stage of the evaluation, as shown in Figure 4. The test was divided into two contexts: Context A (1), in which the participants looked at an image of a fire extinguisher mounted on the wall for exactly 7 seconds and had their eye movement tracked. Next, the same participants watched a nearly one-minute video where a firefighter instructed about the proper way to use the extinguisher (2). After receiving the information on the proper use of the 


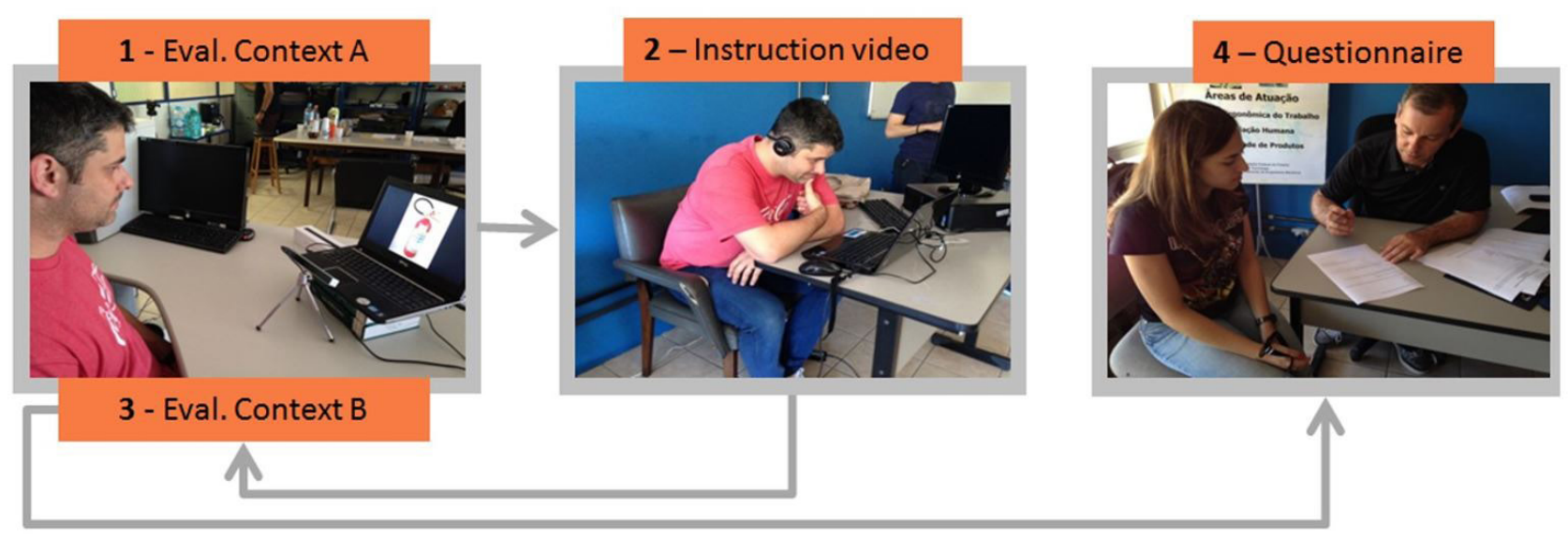

Figure 4. Stages the of visual perception evaluation process. Source: The authors (2016).

equipment, the participants were taken to the evaluation, Context B (3), which consisted of looking again at the same image for the same amount of time as Context $\mathrm{A}$ and have their eye movement tracked.

In the latter part of the process, participants answered a semi-structured questionnaire with information about change in perception of the extinguisher part and the testing process. The evaluators wrote down observations such as utterances or calibration difficulties in both situations.

The choice of procedures for evaluation allowed collecting prior information on the use of the equipment, knowledge on product parts and changes in eye perception, therefore understanding the affordances and their characteristics. This fire extinguisher analysis has shown how intuitive its use is in an emergency, even though people know or have already seen the equipment.

\section{Results and discussion}

For a better understanding of the research results, two areas of interest on the fire extinguisher image were delineated. The first, comprising the top of the product included: hose, pressure gauge, safety pin, caring lever and trigger. The second area of interest mainly comprised the cylinder, which carries the instructions for use. As nomenclature, the upper part was defined as Area 1 and the cylinder area as Area 2. Thus, fixation time checks disregarded other areas, which included gazes at the wall where the fire extinguisher is mounted.

The first data analyzed were the heatmaps of executed visualizations, which renderan average of the participant's visualization as well as major points of fixation time. Thus, according to Figure 5, the results show that during Context A participants acted more dispersed, since they were trying to understand how to use the extinguisher, focusing on the printed instructions on the cylinder label (Area 2). However,

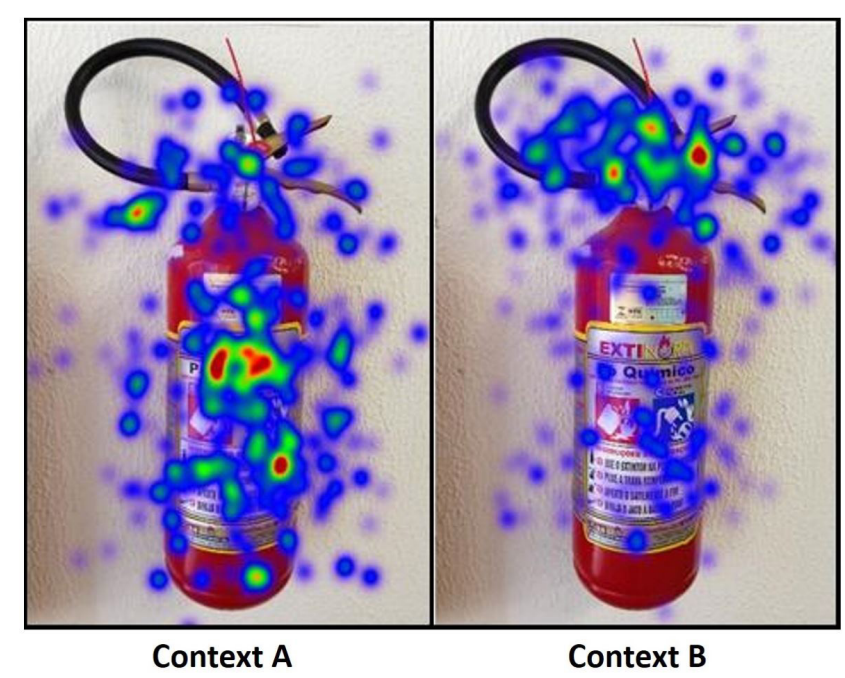

Figure 5. Heatmaps: differences between contexts A and B. Source: The authors (2016).

after receiving information for proper use, the focus during context B was the top of the extinguisher (Area 1), in which functions and devices stand out.

Thus, real physical affordances became more noticeable after a video provided information for the use of the equipment and affordances became noticed by the participant. However, during context B the cylinder is still noticed, but less often and without intense fixation points.

After this, the fixation time on both areas was analyzed, with the aim to identify visualization changes. Evaluating Context A first, the time of the first fixations concentrated on area 1 for 174 milliseconds and on area 2 for 129 milliseconds, as shown in Graphic 1.

In relation to the total amount of time, on area 1 were recorded 840 milliseconds and, on area 2, 2670 milliseconds, as shown in Graphic 2. 


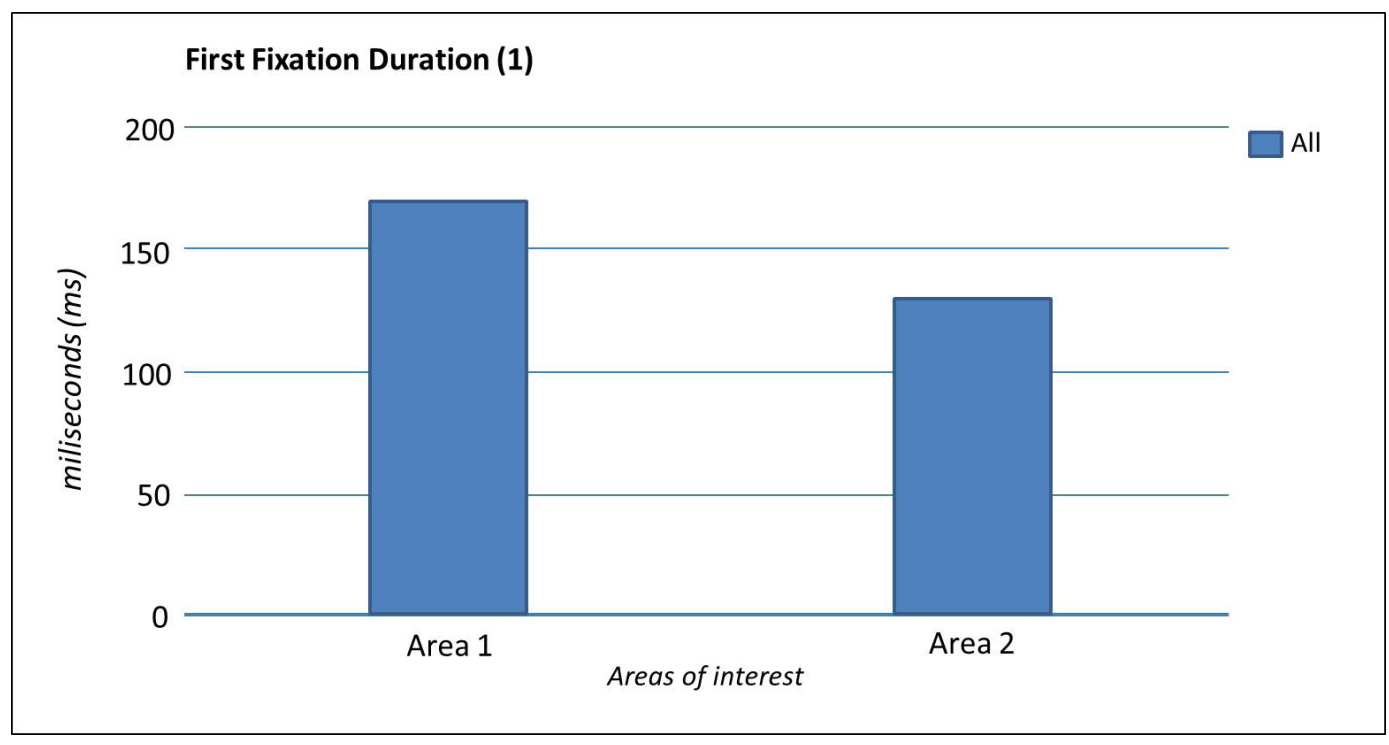

Graphic 1. Average time (first fixations) in the areas of interest during context A. Source: The authors (2016).

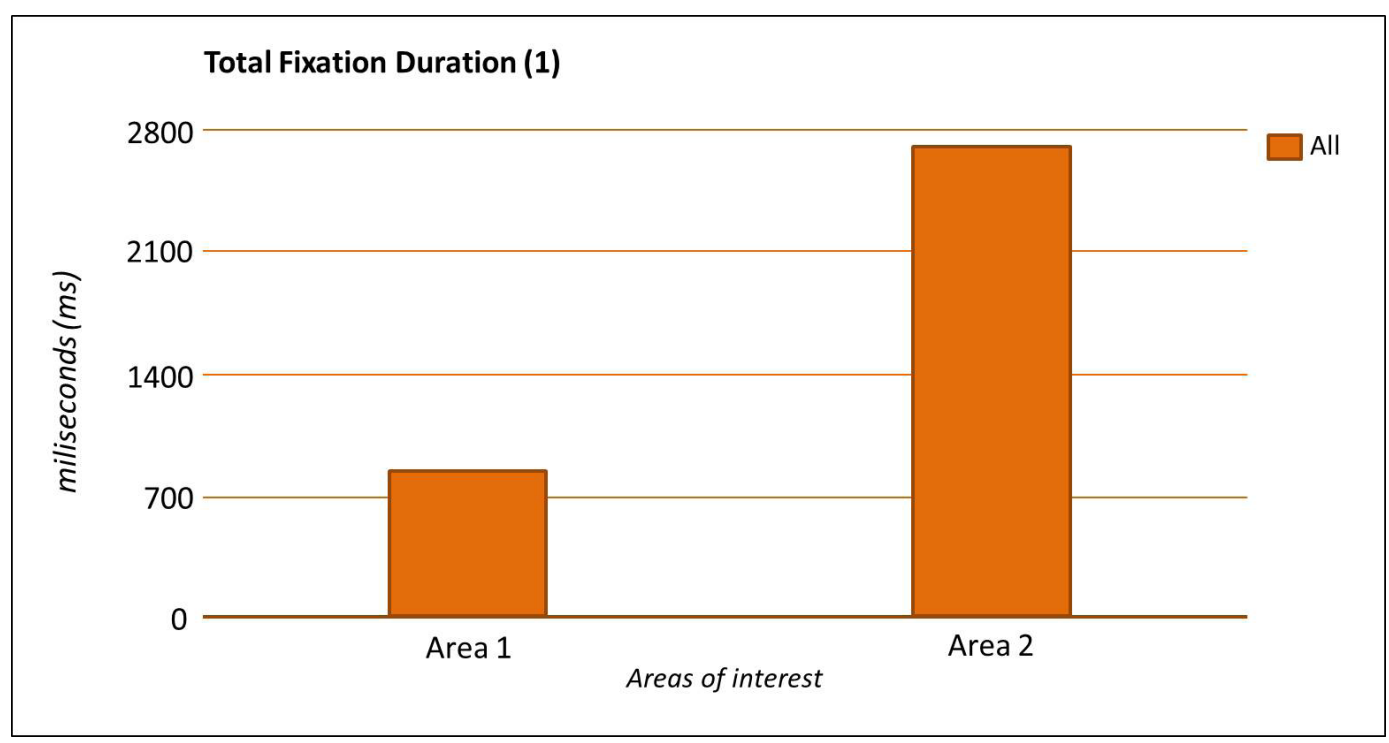

Graphic 2. Total amount of time on areas of interest during context A. Source: The authors (2016)

This demonstrates that participants first sought to understand the functions of the product parts and then fixed for most of the time in the central part, where the basic instructions for use are. This reversal of view between the two areas shows that participants spent more time finding information directly on the product instructions, for they had failed to quickly identify its physical affordances.

On context $\mathrm{B}$, for the average time of the first fixations (Graphic 3), the results were similar. The visualization directed to area 1 , totaled 174 milliseconds and, to area 2 , 126 milliseconds:

However, out of the total amount of time for context B, the results showed to be the opposite from context A, for area 1 was recorded with 2089 milliseconds and area 2, 1110 milliseconds, as shown in Graphic 4.
This demonstrates that the participants first sought the information in the video (prior information), noticing the physical affordances of the product and kept focus on area 1 (upper part), in which functions and devices are more complex, without need for intense attention on area 2 where the instructions were.

As a complementary step analysis, participants were asked about which parts of the fire extinguisher they did not know and have come to know during the instruction video. The least known elements were the safety pin, the seal and the pressure gauge. Then, the participants were asked to quote characteristics that the extinguisher should have for a faster and easier understanding of the product. A total of 25 answers were listed, and these, grouped into six categories, namely: 


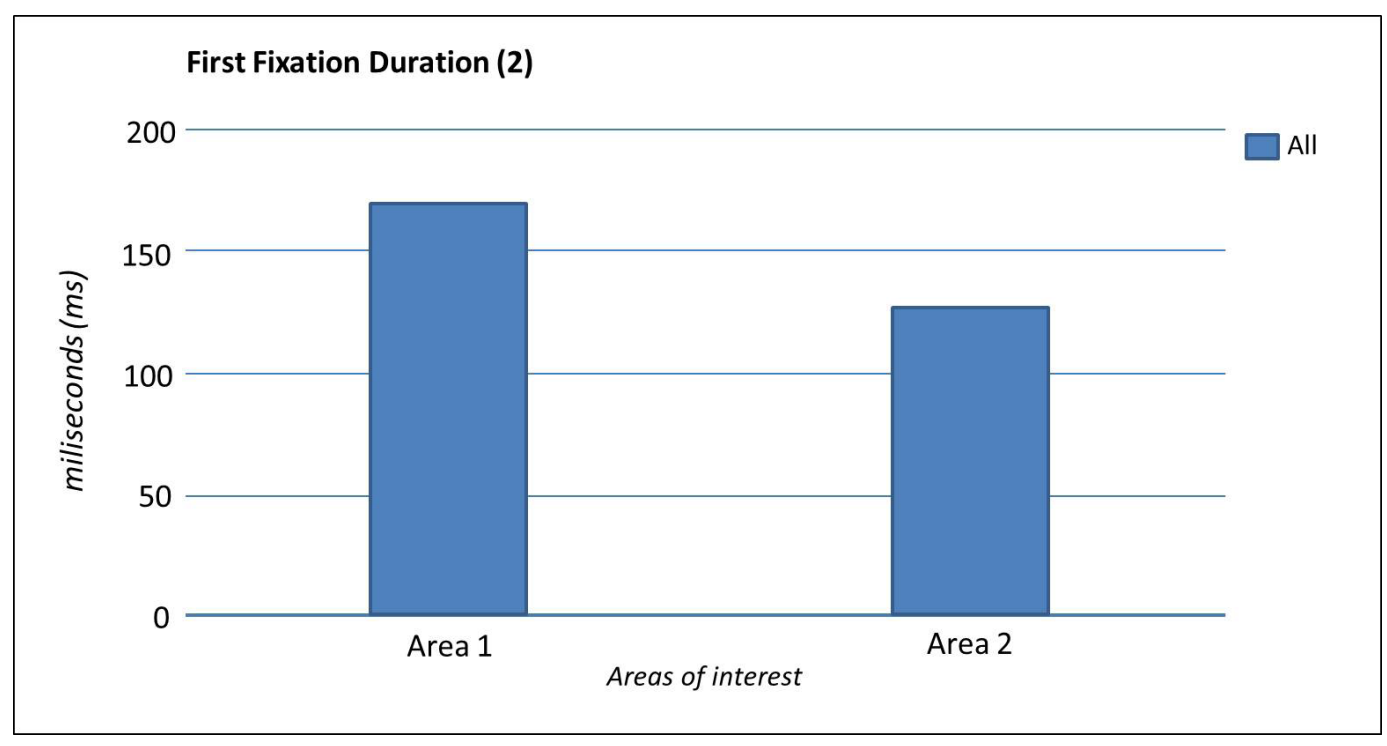

Graphic 3. Average time (first fixations) in the areas of interest during context B. Source: The authors (2016).

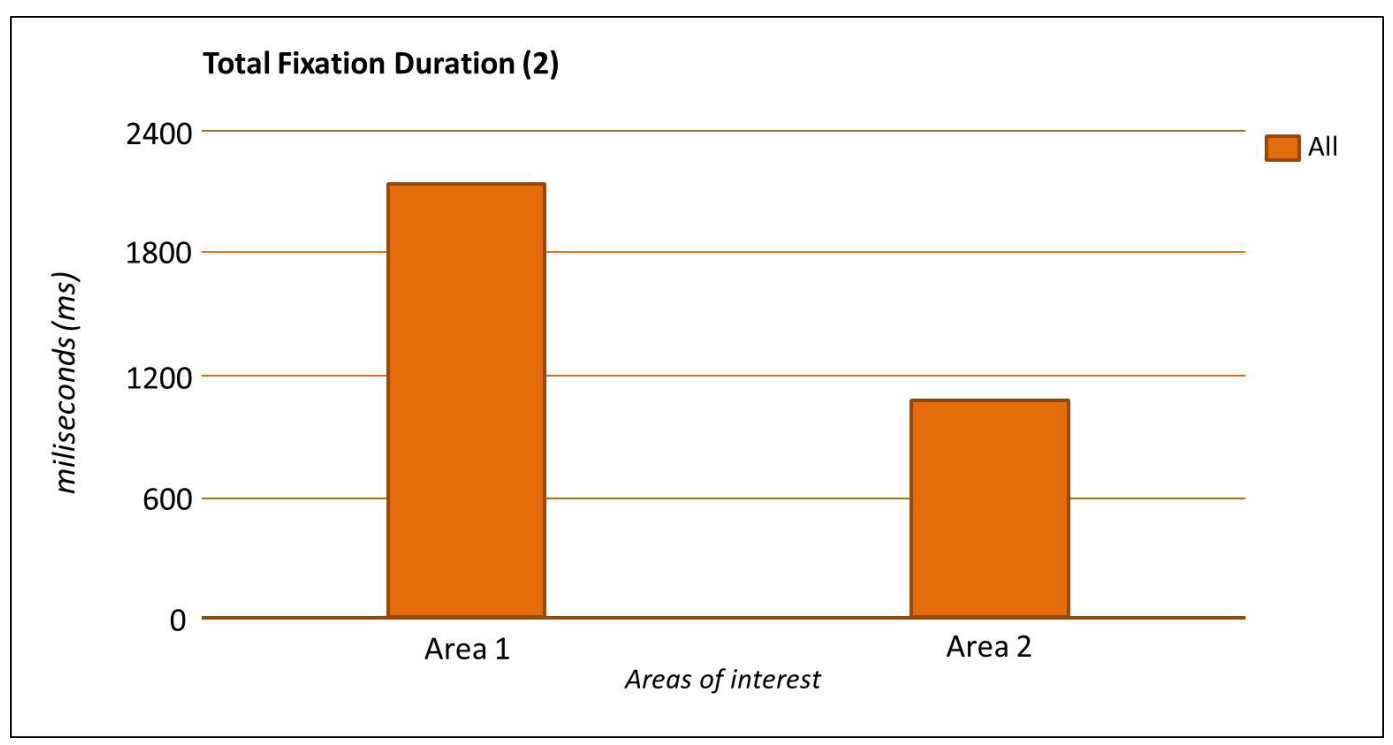

Graphic 4. Total amount of time in the areas of interest during context B. Source: The authors (2016).

- Simpler and more intuitive;

- Breaking the seal;

- Instructions on how to use the product;

- Safety pin information;

- Proper way to use the hose;

- Other Color.

The most frequent answers are related to the markings that should exist on the product, seeking to make it more intuitive from the point of view of a possible user. They also listed characteristics related to the safety pin, located on the top of the product, and to a lesser extent were listed characteristics related to color, location of the hose, and breaking of the seal.
Finally, participants were asked about what they had noticed on the product, before and after watching the video. The participants indicated that, at first (context A), the visualization of the product occurs as a whole, in order to try to understand it. During context B they tried to focus on the points they did not know and had come to know from the video instructions, basically concentrating mostly on area 1.

With the final stage, it can be seen that there is compatibility between the information provided by the participants and the results analyzed from the Eye Tracking. This confirms the change in product visualization due to prior knowledge, indicating the most perceived physical affordances by the research participants in both contexts. 


\section{Final considerations}

The fire extinguisher evaluated in this study proved to be difficult to understand because participants did not perceive the physical affordances of the product as a proper step-bystep action. Therefore, the equipment lacks interaction and intuition. Thus, future projects of fire extinguishers should prioritize its intuitive use during emergencies, in which the user doesn't need to spend most of the time identifying label instructions, and can immediately use it. It is also important to stress that this situation must meet not only people who have training or prior knowledge, but also potential users who are not trained, and have access to the product.

For further analysis, other concerns should also be part of the information survey, for example, the environment in which the user is in, cultural and social references and "risk sensitivity", which according Sjöberg (2000) varies greatly from person to person, and finally, perform tests with more assertive apparel than the ones used for this research.

\section{References}

ASSOCIAÇÃO BRASILEIRA DE ERGONOMIA ABERGO. Norma ERG BR 1002: Código de Deontologia do Ergonomista Certificado. Rio de Janeiro: ABERGO, 2003.

ASSOCIAÇÃO BRASILEIRA DE NORMAS TÉCNICAS ABNT. NBR 15808: extintores de incêndio portáteis. Rio de Janeiro: ABNT, 2013. 64 p.

BROCH, J. C. O conceito de affordance como estratégia generativa no design de produtos orientado para versatilidade. 2010. 100 f. Dissertação (Mestrado)Universidade Federal do Rio Grande do Sul, Porto Alegre, 2010.

\section{CORPO DE BOMBEIROS MILITAR DO DISTRITO} FEDERAL - CBMDF. Manual básico de combate a incêndio. Brasília: CBMDF, 2009. Available from: $<$ https://www.cbm.df.gov.br/institucional/2012-11-13-1655-12? task $=$ document.viewdoc\&id $=745>$. Access in: 17 ago. 2017.

CHEN, J. et al. Impact of experience when using the Rapid Upper Limb Assessment to assess postural risk in children using information and communication technologies. Applied Ergonomics, v. 45, n. 3, p. 398-405, 2014. PMid:23735750. http://dx.doi.org/10.1016/j.apergo.2013.05.004.

DAKE, K. Technology on trial: orienting dispositions toward environmental and health hazards. 1990. Doctorate (Ph.D. Thesis)-University of California, Berkeley, 1990.

DAKE, K. Orienting dispositions in the perception of risk. Journal of Cross-Cultural Psychology, v. 22, n. 1, p. 6182, 1991. http://dx.doi.org/10.1177/0022022191221006.
DIAS, S. B. De que forma o consumidor olha para a marca?. Lisboa: EyeTracking, 2009. p. 78-80. Available from: $<\mathrm{http}$ ://workvalue.net/eyetracking/Press_Work_Value Marketeer_Eye_Tracking.pdf $>$. Access in: 17 ago. 2017.

DOUGLAS, M.; WILDAVSKY, A. Risk and culture. Berkeley: University of California Press, 1982.

GAVER, W. W. Technology affordances. In: CHI'91. Proceedings... New Orleans: ACM, 1991. p. 79-84.

GIBSON, J. J. The theory of affordances. New York: Lawrence Erlbaum Associates, 1977.

HAN, S. H. et al. Evaluation of product usability: development and validation of usability dimensions and design elements based on empirical models. International Journal of Industrial Ergonomics, v. 26, n. 4, p. 477-488, 2000. http:// dx.doi.org/10.1016/S0169-8141(00)00019-6.

INTERNATIONAL ORGANIZATION FOR STANDARDIZATION - ISO. ISO 9241-11: ergonomic requirements for office work with visual display terminals (VDTs). Part 11: guidance on usability. Switzerland: ISO, 1996.

INTERNATIONAL ORGANIZATION FOR STANDARDIZATION - ISO. ISO 9241-210: ergonomics of human system interaction. Part 210: human-centred design for interactive systems (formerly known as 13407). Switzerland: ISO, 2010.

JUST, M. A.; CARPENTER, P. A. The role of eye-fixation research in cognitive psychology. Behavior Research Methods and Instrumentation, v. 8, n. 2, p. 139-143, 1976. http://dx.doi.org/10.3758/BF03201761.

LAKATOS, E. M.; MARCONI, M. A. Técnicas de pesquisa. 6. ed. São Paulo: Atlas, 2006.

LÖBACH, B. Design industrial: bases para a configuração dos produtos industriais. São Paulo: Edgard Blucher, 2001.

MAIER, J. R. A.; FADEL, G. M. Affordance based design: a relational theory for design. Research in Engineering Design, v. 20, n. 1, p. 13-27, 2009. http://dx.doi.org/10.1007/ s00163-008-0060-3.

NAVARRO, M. B. M. A.; CARDOSO, T. A. O. Percepção de risco e cognição: reflexão sobre a sociedade de risco. Ciência e Cognição Magazine, v. 6, p. 67-72, 2005. Available from: $<\mathrm{http}: / / \mathrm{www}$. cienciasecognicao.org/revista/ index.php/cec/article/viewFile/548/319>. Access in: 17 ago. 2017.

NORMAN, D. A. The psychology of everyday things. New York: Basic Books, 1988.

PARANÁ. Governo do Estado do Paraná. Polícia Militar do Estado do Paraná. Comando do Corpo de Bombeiros. Código de Segurança Contra Incêndio e Pânico CSCIP. Curitiba: CBMPR, 2011. Available from: <http:// 
www.bombeiros.pr.gov.br/arquivos/File/CSCIP2015/ CSCIP_2015.pdf $>$. Access in: 17 ago. 2017.

PARANÁ. Governo do Estado do Paraná. Departamento de Segurança Pública. NPT 002: adaptação às normas de segurança contra incêndio: edificações existentes e antigas. Curitiba: Corpo de Bombeiros do Paraná, 2014. Available from: <http://www.bombeiros.pr.gov.br/arquivos/File/ CSCIP2015/NPT_002.pdf>. Access in: 17 ago. 2017.

PERNICE, K., NIELSEN, J. Eyetracking methodology: how to conduct and evaluate usability studies Using Eyetracking. Freemont: Nielsen Norma Group, 2009.

POOLE, A.; BALL, L. J. Eye tracking in human-computer interaction and usability research: current status and future prospects. In: GHAOUI, C. (Ed.). Encyclopedia of Human Computer Interaction. Pennsylvania: Idea Group, 2006.

PUCILLO, F.; CASCINI, G. A framework for user experience, needs and affordances. Design Studies, v. 35, n. 2, p. 160179, 2014.

REBELO, I. Apostila de IHC. [S.1.]: [s.n.], 2009. Available from: <http://irlabr.wordpress.com/apostila-de-ihc/>. Access in: 17 ago. 2017.
SILVA, C. M. A. Experiência com o produto a partir do uso intuitivo. Curitiba: UFPR, 2012. 156 p. Available from: < http://dspace.c3sl.ufpr.br/dspace/ bitstream/handle/1884/28065/R\%20-\%20D\%20-\%20 CAIO\%20MARCIO\%20ALMEIDA\%20E\%20SILVA. pdf? sequence $=1>$. Access in: 17 ago. 2017.

SJOBERG, L. Factors in risk perception. Risk Analysis, v. 20, n. 1, p. 1-12, 2000. http://dx.doi.org/10.1111/02724332.00001 .

SUN, L. et al. Designers' perception during sketching: an examination of Creative Segment theory using eye movements. Design Studies, v. 35, n. 6, p. 593-613, 2014. http://dx.doi.org/10.1016/j.destud.2014.04.004.

YOON, S. H.; LIM, J.; JI, Y. G. Assessment model for driver perceived visual complexity. Applied Ergonomics, v. 46-A, p. 76-83, 2015. PMid:25130311. http://dx.doi.org/10.1016/j. apergo.2014.07.005.

YOUNG, K. et al. The effects of using a portable music player on simulated driving performance and task-sharing strategies. Applied Ergonomics, v. 43, n. 4, p. 1-9, 2012. PMid:22118952. 